


\title{
Knowledge Building and Knowledge Forum: Getting Started With Pedagogy and Technology
}

\author{
Christian Tarchi, University of Florence \\ Maria Chuy, Zoe Donoahue, Carol Stephenson, Richard Messina, \\ and Marlene Scardamalia, OISE/University of Toronto
}

\section{ABSTRACT}

Knowledge Building provides a model of education for a knowledge age-a model of collective responsibility for idea improvement. This article provides two examples of getting started with the pedagogy and the technology, one from Senior Kindergarten, with students working together to understand why leaves change color in the fall, and the other from Grade 1, featuring explorations of the water cycle. In addition to the classroom work that is reported, commentary on school practices from a Librarian-Technology coordinator and Vice Principal are included to provide a broader school perspective on the work presented in this article.

\section{Introduction}

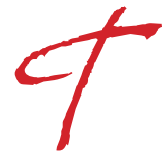

he emergence of the "knowledge age" has created the need for citizens able to work with ideas (Bereiter, 2002; Florida, 1995; Warner, 2006). Knowledge Building addresses this need by engaging students directly and productively in sustained work with ideas, with students assuming collective responsibility for idea improvement (Scardamalia \& Bereiter, 2003). Two concise, published overviews on Knowledge Building theory, pedagogy, and technology are a chapter in the Cambridge Handbook of the Learning Sciences (Scardamalia \& Bereiter, 2006) and a special issue of the Canadian Journal of Learning Technology (Jacobsen, 2010). 
The founders of Knowledge Building pedagogy have identified 12 principles to serve as pedagogical and technological design parameters (Scardamalia, 2002; Scardamalia \& Bereiter, 2006; Scardamalia \& Bereiter, 2010):

Real Ideas, Authentic Problems. Students' ideas and problems of understanding drive knowledge advancement and need to be at the heart of classroom interactions.

Improvable Ideas. From the earliest ages, students understand that ideas are improvable and that working to improve idea quality, coherence, and utility brings their work into line with others trying to create a better world.

Idea Diversity. To create new ideas it is essential to compare and combine diverse ideas, take risks with ideas, and work through complexity rather than focus primarily on asking questions and finding right answers.

Rise Above. Students deal with competing ideas by formulating higherlevel ideas that capitalize on the strengths and overcome the weakness of the competing ideas.

Epistemic Agency. Students learn to take over high-level knowledge work (generating ideas and plans, evaluating results, etc.) usually reserved for teachers.

Community Knowledge; Collective Responsibility. Each student accepts responsibility for what the group as a whole is able to achieve, with focus on generating ideas the whole community will find useful.

Democratizing Knowledge. All members of the community find productive roles and take pride in what the group as a whole is able to achieve.

Symmetric Knowledge Advancement. Students recognize that advancing the frontiers of knowledge is a civilization-wide effort in which they can participate, and that contributing to the knowledge advancement of others and of their community returns gains to their own knowledge advancement.

Pervasive Knowledge Building. Students come to see all problems, in and out of school, as occasions for building knowledge. 
Constructive Uses of Authoritative Sources. Authoritative sources are valued means for understanding the state of the art in a field; they are also objects for critical analysis and improvement.

Knowledge Building Discourse. The discursive practices of the community engage all participants in transforming ideas, with critical analysis and efforts to go deeper highly valued.

Concurrent, Embedded, and Transformative Assessment. Assessment is an integral part of the students' efforts to advance knowledge, with self- and groupassessment part of the knowledge-building process.

Knowledge Building pedagogy is fostered through use of knowledgebuilding technology - technology that creates an environment favorable to the processes of expertise and innovation, as reflected in the above principles. Knowledge Forum is an online community space (www.ikit.org; see also Scardamalia, 2004) specially designed to support these processes. "Views" are created by students who may produce diagrams, models, or other backgrounds on the view using a graphics tool. "Notes" are contributed to these "views," and notes can live in multiple "views," to reflect the different perspectives created by different view backgrounds. Students reference, and build-on other students' notes, and create "rise-above" notes-notes that synthesize content in several notes. High-level knowledge work is further supported through use of "scaffolds" - discourse markers that help participants use and review their work in light of discourse moves deemed important to advancing their discourse. For example, scaffold supports from the theory-building scaffold include, "My theory...", "I need to understand ...", "A better theory is ...".

In this article we show knowledge-building principles in action in two "getting-started" contexts: (a) Senior Kindergarten exploration of why leaves turn color in the fall and (b) Grade 1 exploration of the water cycle. The site of this work is a laboratory school at the University of Toronto. Excerpts from interviews with a LibrarianTechnology coordinator and Vice Principal are included to provide a broader school perspective on the work presented in this article. The Librarian-Technology coordinator chairs weekly Faculty Knowledge Building/Professional Development Meetings; the Vice Principal previously taught in the same school, specializing in use of Knowledge Building/Knowledge Forum. To help the reader track interview comments and knowledge-building principles, we use italics each time an interview or principle is presented. 
Questions addressed in this paper include: How can teachers build a classroom community that supports idea generation, diversity, careful listening, and interaction to foster idea improvement with self-direction? What are the benefits of Knowledge Building pedagogy and technology? These and other issues will be discussed and recommendations provided for enhancing effective Knowledge Building principles in elementary-school classrooms.

At the Dr. Eric Jackman Institute of Child Study (JICS), University of Toronto, Canada, children are introduced to Knowledge Building principles when they enter the school at age three. Playing with ideas is natural and in evidence as soon as children learn to speak, but the more demanding process of discussing ideas in a community, with members committed to continuously improving those ideas, is not common. A Knowledge Building community treats ideas as "improvable" and the basis for reflection and conceptual change (see Zhang, Scardamalia, Lamon, Messina, \& Reeve, 2007).

There were 22 children each in the Senior Kindergarten and Grade 1 classes described in this paper: some students spoke a second language, none were considered ESL learners or learning disabled. The two classes were taught by two different teachers.

\section{Knowledge Building in Senior Kindergarten}

At the beginning of the school year, Fall season, children viewed leaves changing color and falling down. Leaves changing color takes place over many weeks-a period of time that allows the children to note and observe leaves that are still on the tree beginning to change color, then starting to fall from the tree, then the rate of falling increasing until there are no more leaves on the tree. The children may also observe the temperature changing, rainfall, or the wind blowing stronger. Their exploration reported here took place September through December, with the work growing organically as ideas and questions arose. Typically students were actively involved in experiments, reflections, and discussions multiple times throughout the week, but a week could pass without further exploration. The fact that phenomena of interest occurred outside each child's home and school engaged students in exploration of natural phenomena, and things they wondered about and wished to understand - a productive context for exploring real ideas, authentic problems (Zhang et al., 2007). 
Interview - real ideas, authentic problems; improvable ideas: "Often visiting teachers to the school will ask, 'How do I start? What's the beginning?' We explain that we have the children begin with an experience that generates questions of understanding, areas of learning that they want to learn more about. ...'theories' of the children at the beginning of the study. ... It is the starting point of the Knowledge Building process. As new information is acquired (through consulting authoritative sources, experimentation, and developing a collective knowledge through the Knowledge Building discourses) new theories develop, allowing the students to refer back to their initial theories and understand how they have evolved-helping them to understand the Knowledge Building principle that 'all ideas are improvable."

To start, the teacher engaged the students in a whole class discussionwhat the children refer to as "KB Talk" (Knowledge Building talk). The children typically sit in a circle and share their ideas while the teacher writes down each idea and engages each child. In the case reported here the question "Why do leaves fall?" became the focus for the children's study of trees. Soon after generating ideas, the students walked to a neighborhood park and were asked to decide which tree in the park was their favorite. Each child then photographed that tree, and collected one leaf from the tree to bring back to the classroom. The children then carefully traced their leaves and drew in the lines, or veins, as some children already knew to call them. The photographs and traced leaves were then prominently displayed where the children could make comparisons and connections based on shape, size, and color (see Figure 1).

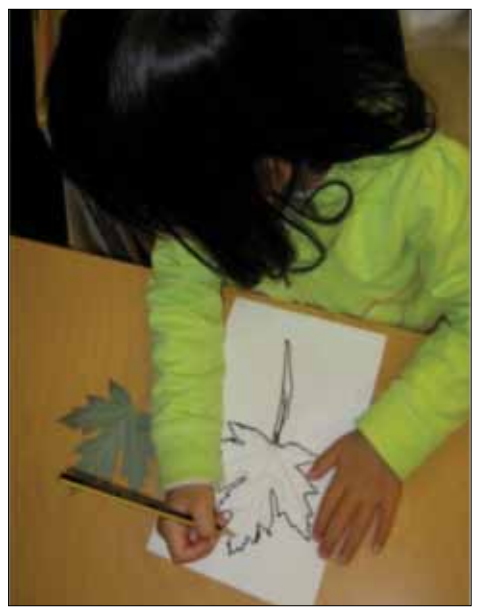

Fig. 1: Real ideas, authentic problems: Students are engaged in understanding the world 
A few days later, the teacher proposed to the children to collect 10 different leaves. Back in the classroom, the children were asked to create a poster grouping their leaves in some way-for example, by kind or shape (see Figure 2). The teacher emphasized the importance of each child's contribution because everyone in the classroom needed to benefit from his/her work. This is a possible way to address the principle of community knowledge; collective responsibility; (see Scardamalia, 2002; Zhang, Scardamalia, Reeve \& Messina, 2009).

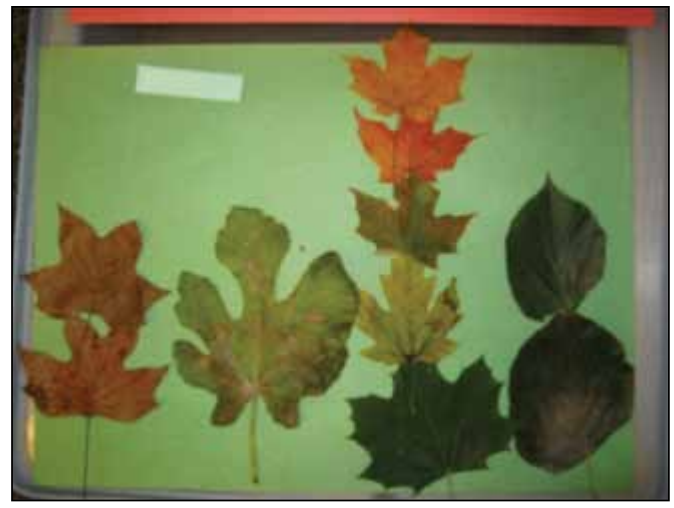

Fig. 2: Community knowledge, collective responsibility: shared artifacts

Interview - community knowledge; collective responsibility: Traditionally, students are responsible for their own learning only. In Knowledge Building students learn for their own sake but also to contribute to the knowledge of the community... New information cannot be only shared at the end of the unit such as is often done in Project-Based Learning but instead continuously so that everyone shares a breadth of understanding along with a specialized deep knowledge based on their research interest...making the individual's learning visible to everyone else in the classroom for the benefit of all.

By engaging students in grouping leaves by size and shape the teacher made it easy for students to share their ideas during group discussions. Indeed, the group discussions were animated and rich in content. The children discussed why leaves were falling, why they changed color, why they got wrinkled. Each child expressed ideas; the teacher helped each child give voice to an idea and be understood by everyone. In this way, the teacher addressed the issue of democratizing knowledge (also see So, Seah, \& Toh-Heng, 2010) while students learned that every 
idea can be shared and developed, regardless of the speaker's personality and preferred mode of communication.

Interview—democratizing knowledge: “Perhaps students feel insecure about sharing their ideas in a written form or orally. Knowledge Building allows many ways for students to contribute: Knowledge Forum notes, through drawings, KB talks, oral presentations, recorded presentations, sharing internet information, etc. Because Knowledge Building is about ideas-all children are on equal ground. And because we value 'idea diversity' all students feel safe to offer their theories as a starting point. The teacher is not presenting her/himself as the 'authoritative' source with all the answersinstead presenting her/himself as a learner as well. This prevents children from 'playing the game of school' in which students try to guess what the teacher is thinking. In Knowledge Building, the entire community shares the mission to have deep understanding - thanks to the contributions of each and every member."

The students were also made aware of the existence of different ideas. First they would hear the idea from a peer, then re-voiced by the teacher, and accordingly be in better position to understand that others in their community have ideas that are different from theirs. This is one of the possible ways to get started with the principle of idea diversity (see Law \& Wong, 2003).

Interview_idea diversity: "A misconception I had as an early career teacher was that my role was to get children to the 'right answer' as quickly and easily as possible. This is unfortunate because it prevented my students from experiencing and appreciating the complexity of learning. In Knowledge Building, we value idea diversity and recognize the value of having many ideas so that we can compare and contrast them, and deepen our understanding. Of course this approach takes time but the result is true learning rather than superficial and shallow knowledge acquisition."

By making sure that each child was heard and fully understood, the teacher had her students actively working toward reciprocity in knowledge advancement. The students get a start on the Knowledge Building principle of symmetric knowledge advancement, learning that to give knowledge is to get knowledge (Scardamalia, 2002). Although important, this principle can be difficult to implement in a classroom. 
Interview-symmetric knowledge advancement: "One aspect of this principle is to have the students specialize in different areas of the inquiry topic, become experts in those subtopics, and then share their knowledge with the whole group. Let's say all of the students are working on astronomy. Some students might be working on black holes, some on gravity, some on orbits, etc. They are engaging in the process of Knowledge Building as a real community of experts would, taking part in a collective responsibility for the knowledge advancement of the whole group."

The children in the class, encouraged by the teacher's enthusiasm for the ideas and observations they brought to the class, added to the conversation from conversations they had at home. For example, based on conversations at home with their parents some children introduced information about oxygen and root systems and some worked with their parents to further classify the leaf they brought to class. By emphasizing and encouraging connections and differences between ideas expressed in class and at home, and at different times and places, the teacher conveyed pervasive knowledge building (see also Nirula, Woodruff, Scardamalia, \& Macdonald, 2003).

Interview — pervasive knowledge building: "Life is naturally integrated; learning is naturally integrated. In schools, we traditionally have compartmentalized curriculum. Knowledge Building shows us that concepts are related to each other and best approached in an integrated way. Children on Knowledge Forum write for a purpose, they advance their theory building while practicing their writing skills. Measuring angles in a light experiment is an authentic application of geometry in math. These are both cross-curricular forms of integration but the pervasive nature of Knowledge Building is that big ideas emerge that connect different strands of science, e.g., the study of light is connected to the study of sound and astronomy, etc. [...] In the Library or the classroom, if a child shares an idea or a theory that is actually incorrect, we don't stop and say, 'No, that's wrong.' The students' misconceptions have an important role to play in the inquiry process... Knowledge Building teachers first establish their classroom as a safe environment where children are encouraged to share their ideas and half-baked theories free from judgment. ... and use these to prepare for future inquiry work, without simply correcting the students in that moment. We know from research that simply telling the right answer does not lead to long-term learning." 
In the Senior Kindergarten class, the teacher helped the students keep track of a knowledge building discourse by archiving it and making it visible in the classroom (e.g., transcripts of discussions on chart paper) or by simply reminding the children orally during a discussion of what they had previously thought/shared. This led to the formation of new questions. The teacher re-read the ideas expressed by the children in the previous discussion, to help them keep track of the starting point of their ideas and to be aware of the improvement of their theories (see Figure 3).

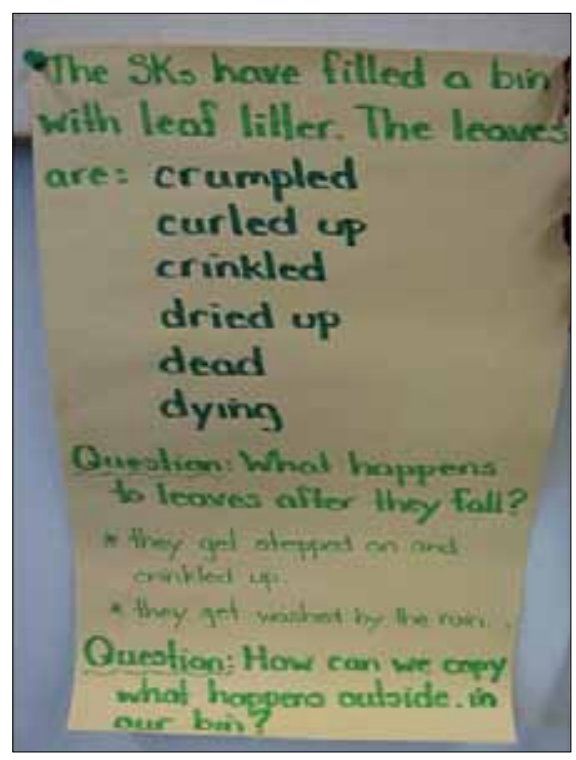

Fig. 3: Improvable ideas: Poster of children's discussion of the improvement of their theories

Knowledge-building discourse is more than sharing knowledge; the ideas of the group actually get refined and transformed through the discourse over time. Additionally, important facets of Knowledge Building work include engaging students in designing experiments and reading books to try to find some answers to their questions.

Teacher: "How does chlorophyll travel? We have come up with three 'maybes': maybe the chlorophyll wipes off; maybe the chlorophyll goes down the veins back to the tree; maybe the chlorophyll turns into humus and then goes back to another tree."

Through observations, experiments, reading, reflections-and discussion throughout-children come to see ideas as improvable; in some cases they were 
able to find answers to their questions and throughout they generated new questions. It is important to note that the ideas offered by individuals become deliberately "detached" from a particular student and "owned" by the group as a whole. The continuous reference to the ideas of the group created a psychologically safe environment for the students, where they could feel free to express their ideas without immediately being labeled "right" or "wrong," and then work on those ideas to improve their quality, coherence, and utility (Scardamalia, 2002).

Teacher: "Yes, [the leaf] is almost black. Last time we talked about two possible explanations why it had stretched. Someone suggested it grew longer because it flattened out [...] the other suggestion was that maybe it is growing."

At various points in their knowledge-building discourse, students addressed high-level ideas and difficult concepts such as oxygen or chlorophyll. At this point the teacher believed that their idea improvement depended on constructive use of authoritative sources. For this reason the teacher explicitly told the children that she would read a book where they might be able to find some answers to the questions raised during the last discussion.

Teacher: "No matter how long we watch the leaf, we don't see the chlorophyll. I found a book that could help us and give us some answers. It's not a story, it has information in it, so it will sound a bit different."

In introducing authoritative sources it is important to emphasize that use of the resource is not simply to answer questions but to engage students in constructive use of resources (see Zhang et al., 2007) — to understand better the present state as well as the growing edge of knowledge in the field (Scardamalia, 2002)-also feeling free to question information there and work toward refining understanding of it.

Interview-constructive use of authoritative sources: "Even experienced Knowledge Building teachers grapple with the appropriate time to introduce authoritative sources: too soon, and you risk hindering the flow of the children's theories and ideas. Too late, and the children's ideas might stagnate, or lose momentum. It is really a hard thing for teachers new to Knowledge Building to delay introducing authoritative sources. Teachers on our staff who are new to Knowledge Building might come to meetings early on in their inquiry topic and say, 'I was thinking of introducing authoritative sources now'. I can remember one teacher asking about this, and many of the other experienced Knowledge Building teachers around table 
answered, 'Just wait, just give it a few weeks, let's see where the kids go with it'. The new teacher did, and it worked beautifully."

Thus students were encouraged to discuss new ideas, especially ones they had raised, that were not addressed in the resource at hand.

Teacher: "Now, how should we find out what happens when the leaves die?"

Asking children to help design experiments represents an early effort to transfer high-level agency for knowledge work to students so that they are in position to assume epistemic agency (see Nirula et al., 2003). In a group discussion, the teacher reminded the children of their own questions, and the students were asked to design a way through which they could test their ideas. The teacher encouraged the children to reflect on different variables and options to be considered when designing an experiment. Leaves were placed in bowls of water, in sand, and dry leaves were put in a bin with toys to stomp over them, like feet. Predictions were made for each experiment, such as the prediction that leaves in water would grow. By designing experiments, the students were "empowered" to address their personal questions rather than having the teacher design all experiments and learning experiences (see Figure 4).

Teacher: "Someone suggested we put it back in water. Do you think it will be shorter or longer now, or maybe the same length?"

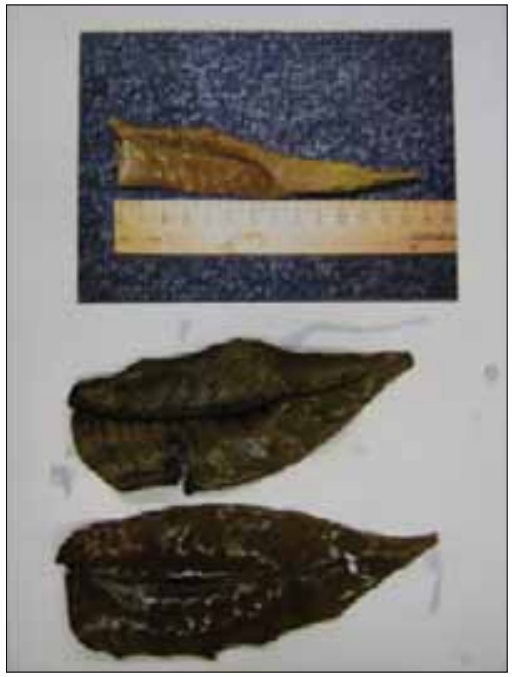

Fig. 4: Example of experiments run by children in senior kindergarten: measuring changes of length in leaves 
Interview-epistemic agency: "If we start with epistemic agency, we might scare teachers new to Knowledge Building. This principle is actually about what the role of the teacher is in the inquiry process. This is truly saying, 'give children the power to design.'"

In the Senior Kindergarten, after the teacher had commented on the breadth of understanding demonstrated during a discussion, including how leaves make sugar for the tree, and how water and oxygen travel through leaves, one student asked if the previous class had learned as much. When the teacher noted that the other class had focused on roots, not leaves, the student responded: "Well, that's what we should study next. How do roots grow?" In Knowledge Building, the class may move on to a new area of inquiry but as this example suggests, an effort is made to provide an account of the current state of understanding as well as noting more to be learned. Students are also encouraged to return to ideas from different vantage points and at different times, and link those ideas to support ever-deepening and connected knowledge advancement.

\section{Knowledge Building in Grade 1}

As seen in the previous section, the ability to play with ideas seems natural and easily initiated with very young children. One of the obstacles in the "improvement" process relates to the need to record, revise, and synthesize ideas. How can these processes be turned over to students? As we saw in the kindergarten example, the teacher is continually modeling these processes for the students. Knowledge Forum (Scardamalia, 2004) represents an online community workspace that supports these processes and engages students directly in them (see also Wegmann \& McCauley, 2009). Knowledge Forum is a web-based application; however teachers at JICS do not generally promote use of Knowledge Forum at home, respecting privacy of all team members. JICS teachers recommend that Knowledge Forum be used when students start to read and write, notably during Grade 1.

\section{Preparing Students for Engagement in a Knowledge Forum Discussion}

The Grade 1 students had experienced Knowledge Building in their previous two years of school, thus they were accustomed to generating ideas, listening to each other, and building onto each others' ideas. So the students arrived to Grade 1 prepared for the next important step in knowledge creation-moving ideas to a 
home-Knowledge Forum - where they could be recorded, revised, and improved. Since the cognitive cost of writing and reading is high (McCutchen, 1996; Just \& Carpenter, 1992) and many students experience difficulties when it comes to reading characters, formulating, spelling, or transcribing ideas, it is important to develop these processes in a context that is engaging (Bereiter \& Scardamalia, 2010). Writing and reading should enter into the process of Knowledge Building naturally, as a logical continuation of work with ideas. The Grade 1 teacher addressed reading and writing expectations through using Knowledge Forum to help students build knowledge.

The Grade 1 students were involved in a yearlong inquiry focused on "cycles," beginning with the topic of water. Their improvable ideas time took place twice a week for 30-45 minutes. This time might be spent reading and discussing texts together, having whole class KB Talks, doing experiments, drawing or writing in their Lab Books, and so forth. About halfway through the school year, each child started to have two 15-minute turns per week on Knowledge Forum.

Grade 1 students explored real ideas, authentic problems, by starting with an experiment. A plastic cup half full with water was placed in a resealable storage bag and the bag was taped onto a window in the classroom. The level of water was marked on the cup (see Figure 5). After a few days the children noticed water pooling in the bottom of the bag. Where did it come from? This inquiry lasted three months.

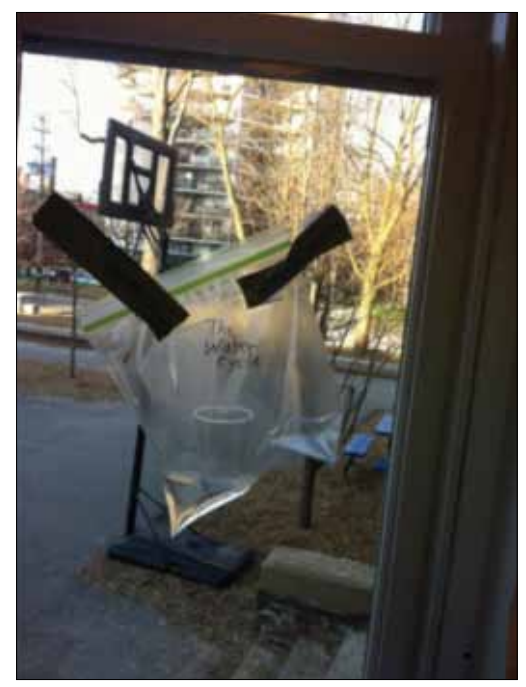

Fig. 5: Experiment on water in Grade 1 


\section{Introducing Knowledge Forum}

Once students generated a few ideas, the teacher demonstrated how Knowledge Forum can help them in recording ideas, so those ideas can be improved in a community space. Below is a description of the first Knowledge Forum session in Grade 1, which lasted 45 minutes.

During the first 10 minutes of the class, the teacher invited students to sit on a carpet, while she was projecting a blank Knowledge Forum view onto a big screen. The teacher explained that every child has access to this electronic space to record ideas so that their ideas can be preserved and improved. Together, the teacher and children collectively decided to name this new view "Grade One Water Experiment." Then she explained how to record a note, give it a title, and save it. From the beginning, as suggested by group efforts to title their view, the teacher is releasing epistemic agency to students (see Nirula et al., 2003).

The next day the teacher worked with each child, encouraging each to state his/her best theory - a theory that would explain why there was water in the bottom of the bag. The teacher typed everything the child said in a Knowledge Forum note, under the student's name (their writing skills were too limited for them to record the ideas on their own), and contributed it to their "Grade One Water Experiment" view. To help students elaborate their theories, the teacher asked clarifying questions (e.g., "Tell me more about where you think the water came from?", "How do you think the water got there?") but she did not push them towards any particular answer. Students were free to go in any direction with their ideas. Once the student had finished telling his/her theory and it had been recorded, the teacher asked each child to think of a title. She stressed the importance of the title to every child she worked with, and defined it as a main idea, or "what's important in your theory." Students need to navigate the vast information they have access to and summarize; creating a title is a developmentally appropriate way to begin to develop such capabilities. They can quickly see that a generic title such as "Water" will not be helpful for others who may be searching for specific information, as they are all working on water. Thus students need to think deeply about what is unique about their note. Sometimes the teacher helped students to find this main idea by asking clarifying questions. For instance:

Teacher in the Grade 1 classroom: "So where do you think the water came from?"

Student: "It has been raining a lot lately, so I think it came through the window and into the bag."

Teacher: "So should the title be 'rain'?"

Student: "Yes" 
Once a note had been posted, the teacher showed the child how to open and read the notes produced by other students, explaining that others may have different ideas. The teacher emphasized that Knowledge Forum is a place to record ideas so that they can be reviewed later. During the next two days, every child had an opportunity to write a note with the help of the teacher and over the next several weeks the children closely observed as water continued to accumulate in the bottom of the bag. They also noticed streaks of water droplets on the sides of the bags, and that there was less water in the cup itself. The class also had regular KB Talks where they could share their theories. The teacher then typed the children's improved theories into a "build on" note. There were some children whose theories were similar to their initial theories, while other children's theories reflected their improved understanding of where the water in the bag came from:

"The water evaporates to the top of the bag and then it falls to the corner of the bag."

"My theory is that the water vapour goes up and changes its state, and turns into liquid and goes down and falls into the bottom of the bag."

"My theory is that the water from the top of the bag dripped down into the cup. P.S. How did the water get to the top of the bag?"

In March, halfway through the school year, when the children's reading and writing skills were stronger, they were able to work more independently. They quickly learned to open and read classmates' notes and to create their own notes. The students were excited about this new adventure - their theories had a place to "live"-a community space that meant their ideas were not simply expressed and forgotten, but recorded and available to be built on by others (see also Chuy et al., 2010 for discussion on theory building). The students seemed to especially appreciate "build on" notes to their notes. Their engagement in reading and writing on Knowledge Forum motivated them to continually exercise literacy skills, dramatically reducing the need for additional, unrelated reading and writing activities in the classroom.

After the initial excitement about recording, reading, and building on ideas in Knowledge Forum, the challenge is to incorporate community dynamics that allow students to take on the more difficult processes of idea improvement, and make this process commonplace and enjoyable (Scardamalia \& Bereiter, 2010). Below are some of the strategies employed by the Grade 1 teacher.

The children used Knowledge Forum two times a week for 15 minutes a session. Priority was given to their own real ideas and authentic problems of 
understanding. Authoritative sources, including books, were not introduced right away; rather, the children had a chance to present their ideas, read each others' notes, and try to improve their theories before having their ideas potentially overshadowed by more formal, "correct," or accepted ideas.

The interplay between work on and off the database and between student ideas and authoritative sources is critical in helping the children engage in idea improvement, as well as for conveying that Knowledge Building is pervasive and coextensive with all aspects of their engagement with the world. Toward this end, student time on Knowledge Forum was intermixed with "KB Talks." Children heard each others' theories and questions and built onto each others' ideas through both online and face-to-face knowledge-building discourse. Often ideas generated in "KB Talks" would be recorded in Knowledge Forum at the next opportunity. And as students became more accustomed to the interactive aspects of online and face-to-face Knowledge Building discourse they-or the teacher-would request that an idea be recorded on Knowledge Forum so that the class could return to it at a later time.

Interview-knowledge-building discourse: "Knowledge-building discourse is the core of a Knowledge Building class. It is the way to hear about the diversity of ideas in the classroom and the diversity of research experiences that is needed to develop the shared community knowledge. It is how we learn from each other and contribute to the learning of each other. While there may be different activities and experiments occurring in the classroom, KB Talks help focus the identified learning goals of the community. KB Talks help ensure accountability of the members of the learning community-we meet to learn from and with each other. KB Talks may be about concepts the students are trying to understand but they can also be about the process of learning and how we are operating as a Knowledge Building community. They give us the opportunity to reflect on our learning methods and see what needs to be improved."

As indicated above, Knowledge Forum includes scaffolds for high-level discourse such as theory building (see Chuy et al., 2010 for details). Students are encouraged to use scaffold supports such as "My Theory" and "New Information." To initiate such activity students simply click on these phrases situated in the surround space for their note and the selected discourse marker appears in the child's note. To encourage children to use these scaffold supports, the first grade teacher sat with each child, reflected on a note he or she had written, and decided together which scaffold should be included. Scaffolds can be added at any point, before any text 
is generated or after the fact. Increases in notes written by students can be seen in Figures 6,7 , and 8 .

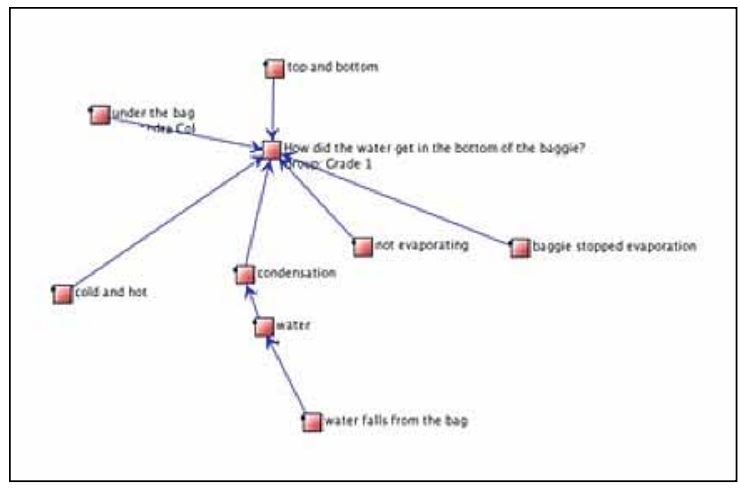

Fig. 6: Notes written by students in a single view: April 20, 2013

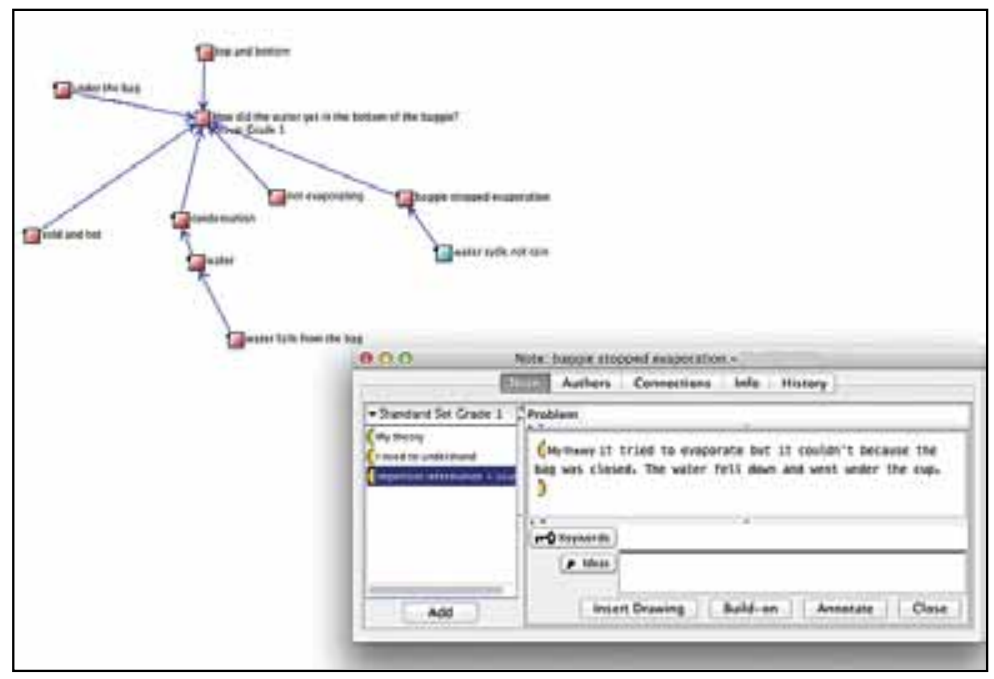

Fig. 7: Notes written by students in a single view, with example of a new note contribution: April 24, 2013 




Fig. 8: Notes written by students in a single view with example of a new note contribution: April 26, 2013

To develop understanding of the important role authoritative sources might play in Knowledge Building, the teacher reads to the children from a variety of sources. The teacher may even present contrasting data and information from different books to highlight for students the need to deal with supportive as well as conflicting information. As the teacher reads aloud to students, she stops often allowing them to ask questions, make comments, theorize, and relate what they are hearing to their own lives and experiences. This injection of new ideas and information sparks idea improvement. Another way to use authoritative sources is to give children time to read books with a partner. A stronger reader may need to be paired with a child who is just beginning to read. As the children read they are encouraged to help each other out with hard words and to talk about what they are reading. As an additional benefit of paired reading, the children are able to discuss the reading and thus refine their understanding before they share ideas more publicly.

\section{Conclusions}

The goal of this paper is to provide a useful resource for teachers who would like to get started with the pedagogy of Knowledge Building and the technology of Knowledge Forum. Toward this end two examples of teacher-student engagement in Senior Kindergarten and Grade 1 were presented, interspersed with interviews from 
the Librarian/Technology coordinator of the school and Vice Principal. According to this team, idea diversity, improvable ideas, and real and authentic problems are central and a good way to introduce newcomers to Knowledge Building pedagogy. Ideas should be at the centre of a Knowledge Building classroom and it is the work of the group to develop and refine them. Teachers agreed that rise-above and concurrent, embedded, and transformative assessment are very difficult principles to implement, and should probably be addressed in a later stage. Rise-aboves are often used as a sort of a published note toward the end of a line of inquiry to convey how students' knowledge had grown. Concurrent, Embedded, and Transformative Assessment is challenging for new teachers to take on at the start, as it also goes beyond self- and peer-evaluation. It is really about "what do we need to do next?" and students should be intentional about that. Even though difficult to implement, these principles are fundamental for creating feedback, assessing outcomes, and identifying what the community needs to do next in order to keep improving ideas.

In conclusion, Knowledge Building supports sustained creative work with ideas, and through meaningful engagement supports development of a broad range of literacy and 21st century competencies. Children gain experience holding the "steering wheel," using technology to support advancement of community knowledge.

\section{Acknowledgments}

We are grateful to the students, teachers, and administrators of the Dr. Eric Jackman Institute of Child Study, University of Toronto, Canada, for the insights and opportunities enabled by their involvement. This work was supported, in part, by the Social Sciences and Humanities Research Council of Canada, grant 410-2009-2481, Ways of Contributing to Dialogue in Elementary School Science and History, held by Marlene Scardamalia. Opinions, conclusions, or recommendations are those of the authors and do not necessarily reflect the views of the Council. 


\section{References}

Bereiter, C. (2002). Education and mind in the knowledge age. Mahwah, NJ: Lawrence Erlbaum Associates.

Bereiter, C., \& Scardamalia, M. (2010). Can children really create new knowledge? Canadian Journal of Learning and Technology, 36(1).

Chuy, M., Scardamalia, M., Bereiter, C., Prinsen, F., C., Resendes, M., Messina, R. et al. (2010). Understanding the nature of science and scientific progress: A theorybuilding approach. Canadian Journal of Learning and Technology, 36(1).

Florida R. (1995). Towards the learning region. Futures, 27, 527-536.

Jacobsen, M. (ed.) (2010). A special issue of the Canadian journal of learning and technology on knowledge building. Canadian Journal of Learning and Technology, 36(1).

Just, M. A., \& Carpenter, P. A. (1992). A capacity theory of comprehension: Individual differences in working memory. Psychological Review, 99(1), 122-149.

Law, N., \& Wong, E. (2003). Developmental Trajectory in Knowledge Building: An Investigation. In B. Wasson, S. Ludvigsen \& Hoppe, U. (Ed.), Designing for Change in Networked Learning Environments (pp. 57-66). Dordrecht: Kluwer Academic Publishers.

McCutchen, D. (1996). A capacity theory of writing: Working memory in composition. Educational Psychology Review, 8, 299-325.

Nirula, L., Woodruff, E., Scardamalia, M., \& Macdonald, P. (2003). Handhelds in a grade two classroom: Innovations to support knowledge-building and epistemic agency. In K. T. Lee \& K. Mitchell (Eds.), Proceedings of the International Conference on Computers in Education 2003. Hong Kong: ICCE.

Scardamalia, M. (2002). Collective cognitive responsibility for the advancement of knowledge. In B. Smith (Eds.), Liberal education in a knowledge society (pp. 76-98). Chicago: Open Court.
Scardamalia, M. (2004). CSILE/Knowledge Forum ${ }^{\circledR}$. In Education and technology: An encyclopedia (pp. 183-192). Santa Barbara: ABC-CLIO.

Scardamalia, M., \& Bereiter, C. (2003). Knowledge building. In Encyclopedia of education, second edition. (pp. 1370-1373). New York: Macmillan Reference, USA.

Scardamalia, M., \& Bereiter, C. (2006). Knowledge building: Theory, pedagogy, and technology. In K. Sawyer (Ed.), Cambridge Handbook of the Learning Sciences (pp. 97-118). New York: Cambridge University Press.

Scardamalia, M., \& Bereiter, C. (2010). A brief history of knowledge building. Canadian Journal of Learning and Technology, 36(1).

So, H.-J., Seah, L.H., \& Toh-Heng, H.L. (2010). Designing collaborative knowledge building environments accessible to all learners: Impacts and design challenges. Computers \& Education, 54, 479-490.

Warner, D. (2006). Schooling for the knowledge era. Camberwell: ACER press.

Wegmann, S., \& McCauley, J. (2009). Going fully online: Reflections on creating an engaging environment for online learning. International Journal of the Scholarship of Teaching and Learning. Vol. 3, No. 1. Retrieved from http://www.georgiasouthern.edu/ijsotl.

Zhang, J., Scardamalia, M., Lamon, M., Messina, R., \& Reeve, R. (2007). Socio-cognitive dynamics of knowledge building in the work of 9- and 10-years olds. Educational Technology, Research and Development, 55(2), 117-145.

Zhang, J., Scardamalia, M., Reeve, R., \& Messina, R. (2009). Designs for collective cognitive responsibility in knowledge-building communities. The Journal of the Learning Sciences, 18, 7-44. 


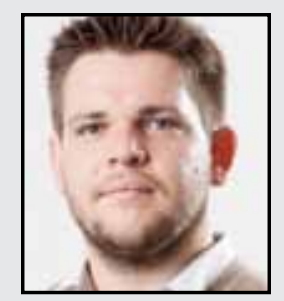

Christian Tarchi (PhD, University of Florence) is Lecturer of Cross-Cultural Psychology, Educational Psychology, and Human Development in Culture at the International Studies Institute, The Umbra Institute, and Fairfield University (Italy). His research focuses on reading comprehension and scientific conceptualization, in collaboration with the Department of Psychology, University of Florence (Italy); and on computersupported learning environments, in collaboration with the Institute for Knowledge Innovation and Technology (OISE/ University of Toronto, Canada).

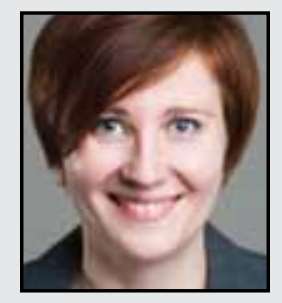

Maria Chuy holds a PhD degree in Cognitive psychology from the University of Poitiers, France and currently works at the Council of Ministers of Education, Canada. Maria's interests are interdisciplinary and relate to any process, system, or activity that enable new knowledge and new understanding to emerge. By closely working with Drs. Marlene Scardamalia and Carl Bereiter, the inventors of the first networked knowledge -building environment for education, she designed and tested new technologies that would help students and adults to enter the Knowledge Age. Maria co-chairs the International Knowledge Building Summer Institutes and serves as a reviewer for a number of well-distinguished academic journals.

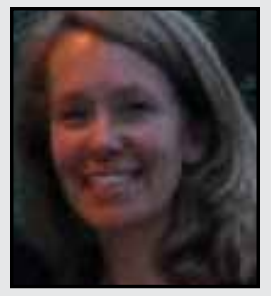

Zoe Donoahue has taught elementary school for over 25 years in both public and independent schools. She currently teaches first grade at the Dr. Eric Jackman Institute of Child Study Lab School at the University of Toronto, where she also mentors Masters of Arts in Education students. Her interests include inquiry-based teaching, mathematics, and literacy. Zoe has presented at conferences across North America. She is a teacher-researcher and has published articles about her own research and classroom practices. 


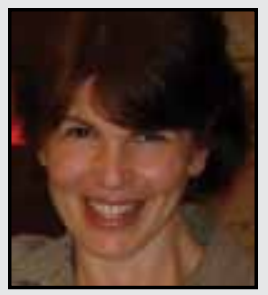

Carol Stephenson teaches at the University of Toronto's Laboratory School, the Dr. Eric Jackman Institute of Child Study, where she has practiced her inquiry-based approach to learning over the past 20 years. Her goal is to constantly find better ways to deepen and make explicit the growth of her students' understanding. Fascinated by how young children play, think, and learn, her work has been featured in Canada's largest newspaper, as well as in the Institute's 2011 publication "Natural Curiosity." Ms. Stephenson has been invited to speak at conferences and schools in Canada, the United States, China, India, and Japan.

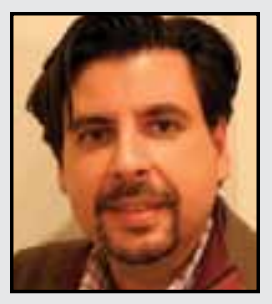

Richard Messina is the Vice Principal at the Dr. Eric Jackman Institute of Child Study Lab School at OISE, University of Toronto and is the Elementary Lead Teacher for the Klingenstein Summer Institute, Teachers College, Columbia. Richard was a classroom teacher for 15 years at the Lab School and in the public school system in Toronto. Richard is involved in research initiatives (Japanese Lesson Study, Knowledge Building) and has presented at AERA and at conferences in Canada, the United States, Europe and Asia. Most recently, he has co-authored a chapter on Lesson Study in the NCTM Yearbook 2012: "Professional Collaborations in Mathematics Teaching and Learning: Seeking Success for All." 


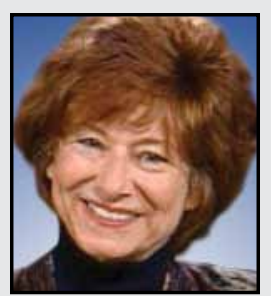

Marlene Scardamalia holds the Presidents' Chair in Education and Knowledge Technologies at OISE/University of Toronto and is co-founder and director of the Institute for Knowledge Innovation and Technology-a worldwide network of innovators working to advance the frontiers of knowledge building in various sectors. "Knowledge building," a term now widely used in education and knowledge management, originated with the CSILE/Knowledge Building project. Marlene led the team that created CSILE (Computer Supported Intentional Learning Environments), which was the first networked knowledge-building environment for education. The second-generation version of this technology, Knowledge Forum ${ }^{\oplus}$, is in use in countries worldwide, in education, health, business, and professional organizations. 